\title{
OBTENÇÃO DE ÓXIDO DE CÁLCIO A PARTIR DA CASCA DE OVO DE GALINHA
}

\section{OBTAINING CALCIUM OXIDE FROM CHICKEN EGG SHELL}

\author{
L.A.F. VIEIRA ${ }^{1}$, M. D. PINHO ${ }^{1}$, S. N. DA SILVA ${ }^{1}$, I.P. PINHEIRO ${ }^{1}$
}

${ }^{1}$ Centro Federal de Educação Tecnológica de Minas Gerais - CEFET MG, Departamento de Materiais, Brasil

E-mail: luisa.amfernandes@gmail.com

\author{
article info \\ Article history: \\ Received 2017-09-04 \\ Accepted 2017-11-20 \\ Available online 2017-12-20
}

PALAVRAS-CHAVE: Resíduo; Casca de ovo; Óxido de cálcio

KEYWORDS: Residue; Egg shell; Calcium oxide.

RESUMO: Diariamente, toneladas de cascas de ovos de galinha são descartadas, gerando um resíduo desvalorizado comercialmente, proveniente de restaurantes, indústria alimentícia e até mesmo residências. A casca de ovo é rica em carbonato de cálcio, um precursor para a obtenção de óxido de cálcio. Comercialmente conhecido como cal, o óxido de cálcio possui maior empregabilidade se comparado a casca de ovo in natura. Atualmente, tem sido utilizado em diversas áreas, como na indústria civil, na indústria de biomanteriais e na agricultura. A casca adquirida na indústria alimentícia ainda contém elementos orgânicos e por isso precisa ser previamente preparada. Esse estudo demonstra a preparação dessa casca até a referida obtenção do óxido de cálcio. A conversão é viabilizada a partir da realização de um tratamento térmico, chamado calcinação, onde a casca de ovo é submetida a uma temperatura de $850^{\circ} \mathrm{C}$ durante uma hora e meia. Durante a calcinação uma reação química ocorre e gás carbônico é liberado, gerando assim, o óxido de cálcio. Foram realizados ensaios de caracterização, como a Difração e Espectrometria de Raios X (DRX) e a Análise Termogravimétrica (TG), para a certificação do produto final.

\begin{abstract}
Tons of chicken eggshells are discarded daily, generating commercially devalued waste from restaurants, the food industry and even homes. The egg shell is rich in calcium carbonate, a precursor for the production of calcium oxide. Commercially known as lime, calcium oxide has a higher employability when compared to eggshell in natura. Currently, it has been used in several areas, such as civil engineering, biomanterial industry and agriculture. The eggshells acquired in the food industry still contains organic elements and therefore needs to be pre-prepared. This study demonstrates the preparation of this shell until said calcium oxide is obtained. The conversion is made possible by performing a heat treatment, called calcination, wherein the egg shell is subjected to a temperature of $850^{\circ} \mathrm{C}$ for one and a half hours. During calcination a chemical reaction occurs and carbon dioxide is released, thus generating calcium oxide. Characterization tests, such as X-Ray Diffraction and Spectrometry (XRD) and Thermogravimetric Analysis (TG), were performed to certify the final product.
\end{abstract}




\section{INTRODUÇÃO}

Ovos de galinha estão entre os alimentos favoritos do mundo. O consumo de ovos resulta na geração de uma enorme quantidade de cascas de ovos como produto residual que necessita ser descartada, provocando um agravante problema ambiental. Para reduzir o impacto ambiental, tentativas têm sido realizadas no intuito de encontrar possíveis aplicações em diferentes áreas (NAGABHUSHANA et al., 2016 apud KINGORI, 2011).

Em 2009, Oliveira, Benelli e Amante afirmaram que 40\% da produção de ovos têm origem nos países em desenvolvimento e apenas $20 \%$ nos países desenvolvidos. A China lidera o ranking com $41,1 \%$ da produção mundial. A comercialização em grande escala de ovos possui vantagens econômicas, como estender a vida útil do produto e facilitar a conservação e transporte do mesmo. Entretanto, provoca a geração de uma quantidade expressiva de cascas, sendo estimada em 5,92 milhões de toneladas por ano em todo o mundo (OLIVEIRA; BENELLI; AMANTE, 2009).

O resíduo de casca de ovo aviário contém uma membrana rica que favorece a atividade microbiológica. Se descartado no meio ambiente geram poluição e podem afetar a saúde pública. Desse modo, a disposição de resíduos de cascas de ovos é muito limitada ao redor do mundo e é um sério assunto nas indústrias de processamento de alimentos (LEITE et al, 2016 apud QUINA et al, 2014). Em muitos países, a maioria desse rejeito sólido é descartada principalmente em aterros sem qualquer tratamento, causando elevados custos financeiros e impactos ambientais. Os aterros sanitários de resíduos sólidos urbanos normalmente se recusam a aceitar resíduos de cascas de ovos, devido a sua membrana protéica (LEITE et al, 2016).

A casca do ovo de galinha é uma biocerâmica natural e porosa, resultado de uma deposição sequencial de diferentes camadas em torno da albumina, que ocorre no istmo e no útero da galinha. Uma estrutura policristalina perfeitamente ordenada é encontrada em toda a casca calcinada (LACA, 2017 apud NYS; GAUTRON, 2007). A casca é composta de uma esponjosa camada de cutícula, uma camada de calcita ou carbonato de cálcio e duas membranas. Além disso, possui 7000-17000 canais de poros em forma de funil, distribuídos de forma desigual na superfície da casca para a troca de água e gases (LACA, 2017 apud LICHANG; KIM, 2008). A parte orgânica é composta pelas camadas de membranas e pela cutícula. Já a porção calcificada consiste na camada mamilar, camada paliçada e camada de cristal vertical, mostradas na Figura 1 (BARBOSA et al, 2011 apud PARSONS, 1982).

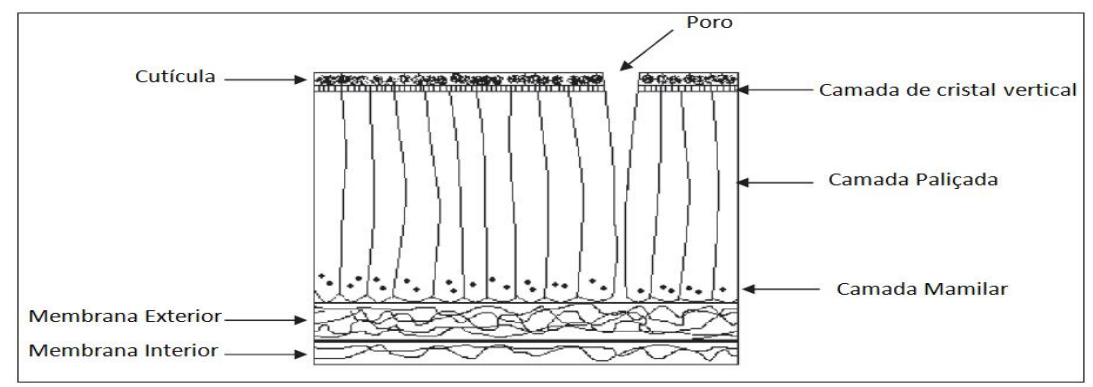

Figura 1 - Estrutura da casca de ovo. 
A composição química da casca de ovo é carbonato de cálcio na forma de calcita $(94 \%$ em massa), fosfato de cálcio ( $1 \%$ em massa), carbonato de magnésio ( $1 \%$ em massa), matéria orgânica, na maioria proteína (cerca de $4 \%$ em massa) e água. (CORREA; MANHÃES; HOLANDA, 2015). Na Figura 2, pode-se visualizar a micrografia da casca in natura.

A)

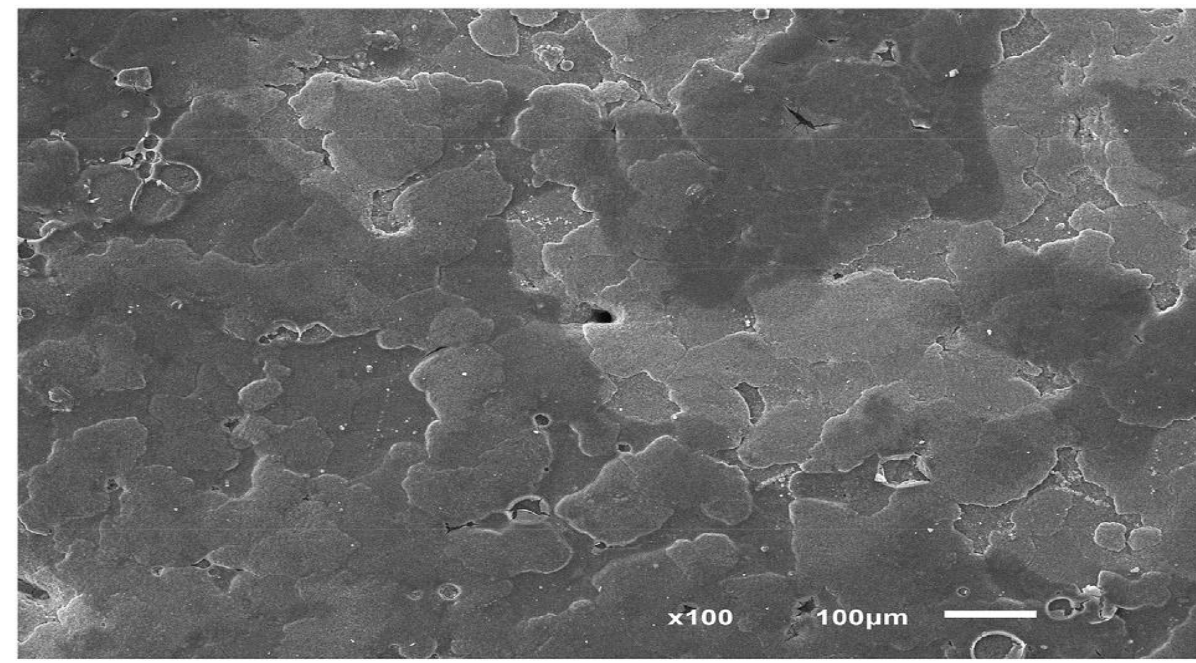

B)

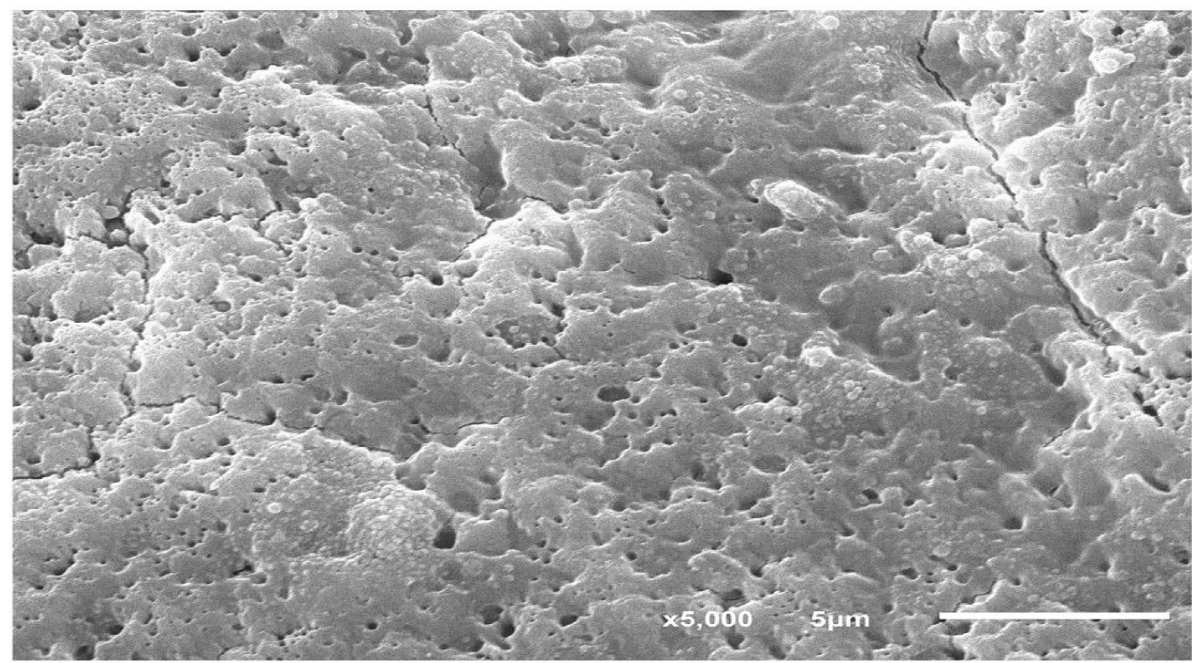

Figura 2 - Microscopia eletrônica de Varredura (MEV) da casca de ovo de galinha in natura.

Nos últimos anos, grandes esforços têm sido realizados para se encontrar utilizações, como produto de alto valor agregado, para os componentes presentes nas cascas de ovos descartadas. Nesse cenário, a casca de ovo surge como fonte rica em carbonato de cálcio $\left(\mathrm{CaCO}_{3}\right)$, que após sua conversão em óxido de cálcio $(\mathrm{CaO})$, possui maior empregabilidade. (CORREA; MANHÃES; HOLANDA, 2015). Dentre algumas aplicações em estudo 
encontram-se:

- desenvolvimento de materiais avançados a base de fosfato capazes de promover a osseointegração, como a hidroxiapatita;

- capacidade do óxido de cálcio $(\mathrm{CaO})$ de atuar como material termoluminescente (TL). Sendo TL um dos métodos mais sensíveis para estimar a concentração de defeitos de radiação ionizante (NAGABHUSHANA et al, 2016);

- atuação como um catalisador benéfico para o meio ambiente, consistindo em material adsorvente para remoção de íons poluentes, como o níquel (LACA, 2017). O níquel é considerado um dos metais mais tóxicos que está presente na água (RAMESH et al, 2016).

- uso como um catalisador sólido e barato, mostrando excelente atividade catalítica na produção de biodisel (NAGABHUSHANA et al, 2016 apud BUASRI et al, 2013).

No campo da tecnologia de captura e sequestro de carbono (CCS), o óxido de cálcio ocupa um papel importante no processo de captura de gás carbônico da atmosfera, baseado na seguinte reação reversível: $\mathrm{CaO}(s)+\mathrm{CO}_{2}(g) \leftrightarrow \mathrm{CaCO}_{3}(s)$. De acordo com Mohammadi et al. (2014) apud Olivares-Marin et al. (2013) após estudos sobre efeitos da morfologia, porosidade e estrutura cristalina do óxido de cálcio $(\mathrm{CaO})$, foi observado que depois do $\mathrm{CaO}$ comercial, a maior absorção de $\mathrm{CO}_{2}$ foi verificada no $\mathrm{CaO}$ proveniente da casca de ovo. Adicionalmente, Mohammadi et al. (2014) apud Ives et al. (2008) comparou o decréscimo na habilidade de captura de $\mathrm{CO}_{2}$ do óxido de cálcio derivado da casca de ovo, da casca de mexilhão e do calcário. Resultados apontaram que o declínio na capacidade foi mais lento para a casca de ovo.

O objetivo do trabalho é a valorização da casca de ovo sendo utilizada como alternativa para a produção de óxido de cálcio.

\section{METODOLOGIA}

As cascas de ovos de galinha foram cedidas pela empresa Vilma Alimentos. Depois de higienização em água corrente, foram submetidas a uma secagem em estufa, com orifício para saída de vapor, a $120^{\circ} \mathrm{C}$ durante 3 horas. Em seguida foram trituradas, primeiramente no liquidificar e posteriormente no gral, e passadas na peneira de abertura 100 mesh, ou $0,149 \mathrm{~mm}$.

Uma amostra do pó obtido foi enviada para ensaio de termogravimetria (TG) para a determinação da temperatura ideal de calcinação. Outra pequena amostra foi enviada para o ensaio de caracterização por Difração de raios x (DRX). 
Após as análises das caracterizações, o pó da casca de ovo foi levado ao forno mufla durante 1 hora e 30 minutos para a realização do tratamento térmico (calcinação) a $850^{\circ} \mathrm{C} . \mathrm{O}$ resfriamento foi realizado dentro do forno, sem qualquer choque térmico. O DRX foi realizado novamente para a certificação do produto final obtido, assim como o balanço de massa para o cálculo de rendimento do processo.

\section{RESULTADOS E DISCUSSÕES}

As cascas foram higienizadas com água corrente, para a retirada de qualquer matéria orgânica residual, como a membrana e clara.

A secagem foi realizada em estufa a $120^{\circ} \mathrm{C}$ durante 3 horas. A umidade retirada foi $28,15 \%$ da massa inicial, como mostrado na Figura 3. Notou-se uma leve mudança na coloração das cascas, inicialmente brancas para um tom amarelado posteriormente.

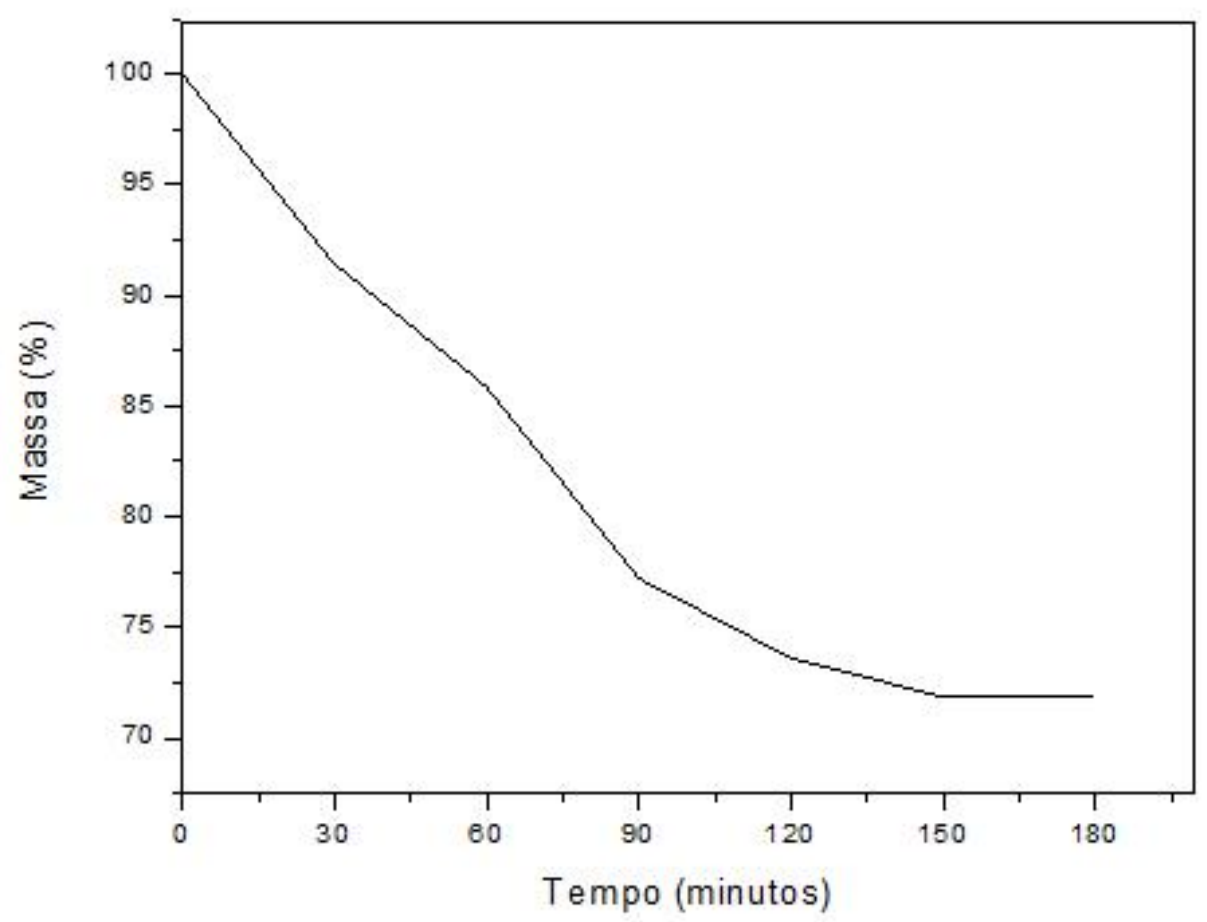

Figura 3 - Secagem das cascas de ovos

Com a trituração obteve-se uma granulometria da casca abaixo de $0,149 \mathrm{~mm}$. Logo após o peneiramento, uma pequena amostra foi enviada para análise de TG a fim de determinar a temperatura ideal para o processo de calcinação. A queda brusca do percentual em massa no gráfico, representado pela Figura 4, evidencia a temperatura de ocorrência da reação química, na qual o óxido de cálcio é obtido. Após a elaboração do gráfico, identifica-se que a temperatura de decomposição da casca de ovo seria em torno de $805^{\circ} \mathrm{C}$. Entretanto foi 
determinada a temperatura de $850^{\circ} \mathrm{C}$, devido a discrepância entre a temperatura real do forno e a do termopar e para garantia do processo de calcinação.

Outra pequena amostra foi enviada para o ensaio de DRX a fim de caracterizar a casca de ovo pura. A Figura 5 mostra que o carbonato de cálcio é predominante na casca de ovo em análise, estando assim em concordância com a literatura.

$\mathrm{Na}$ etapa de calcinação, a amostra foi aquecida e resfriada dentro do forno, evitando assim, choques térmicos. Ao fim do resfriamento, uma pequena amostra foi enviada para o ensaio de caracterização de DRX para a certificação do produto final. O pó, antes amarelado, estava branco, caracterizando a presença de óxido de cálcio.

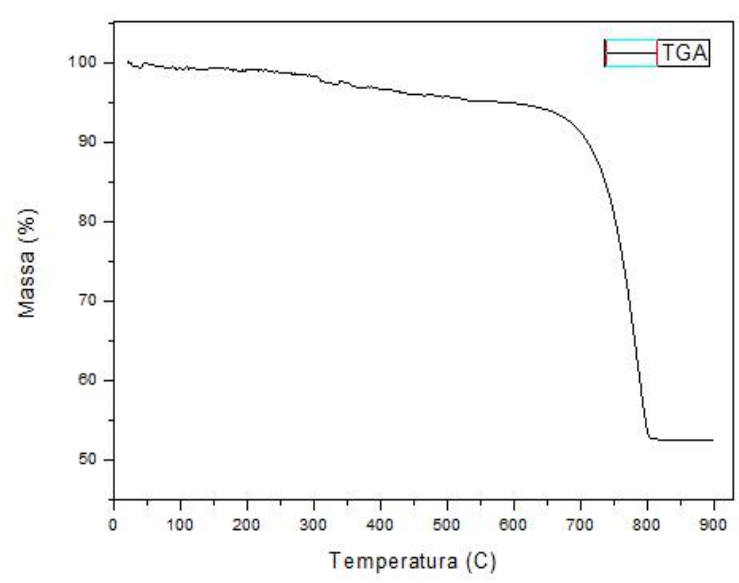

Figura 4 - Resultado da análise de termogravimetria da casca de ovo

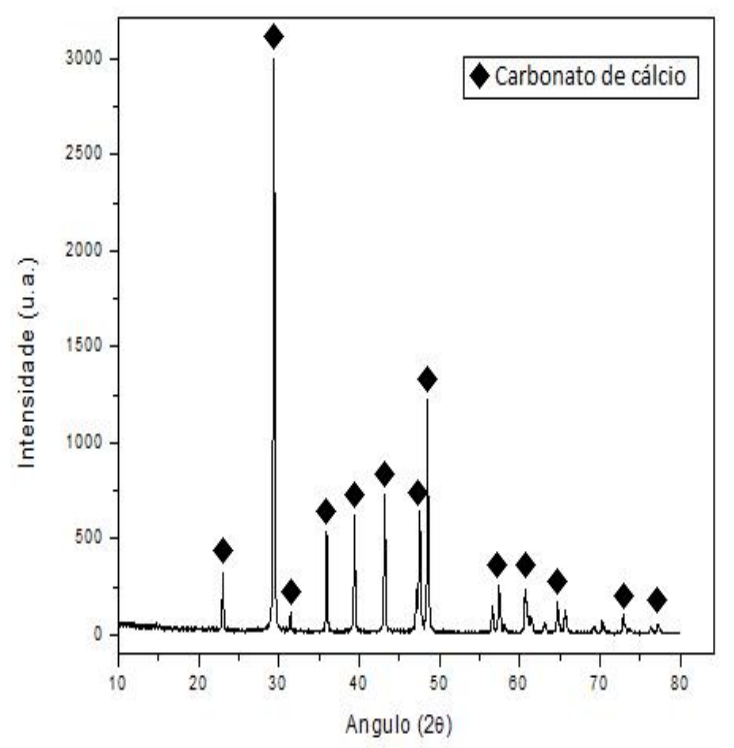

Figura 5 - Resultado de difração de raios X da casca de ovo antes da calcinação. 
O resultado da análise de difração de raios x encontra-se na Figura 6. Observa-se que os picos da amostra são equivalentes aos de óxido de cálcio encontrado no banco de dados Inorganic Crystal Structure Database (ICSD).

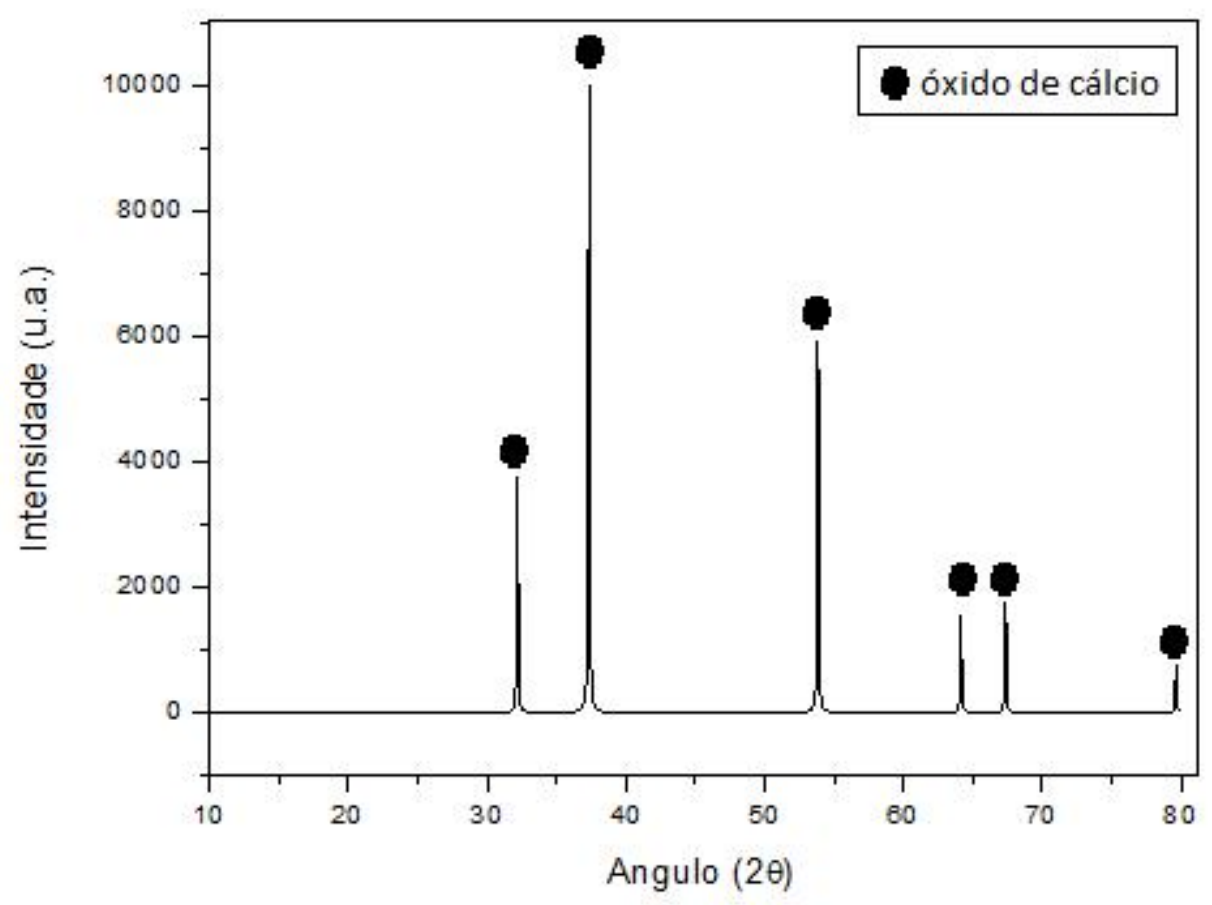

Figura 6 - Resultado da difração de raios X da amostra após a calcinação.

A reação química ocorrida dentro do forno mufla é uma simples calcinação descrita pela equação 1 .

$$
\mathrm{CaCO}_{3(\mathrm{~s})} \stackrel{\Delta}{\rightleftarrows} \mathrm{CaO}_{(\mathrm{s})}+\mathrm{CO}_{2(\mathrm{~g})}
$$

A massa inicial de carbonato de cálcio (casca de ovo) antes da etapa de calcinação era de $30,4 \mathrm{~g}$. No fim da etapa, a massa final da amostra era de $16,6 \mathrm{~g}$, sendo concluída que a eficácia de calcinação foi de $97 \%$.

\section{CONCLUSÃO}

O presente trabalho é de grande importância, uma vez em que há a transformação de algo que seria descartado e sem valor comercial algum, em um produto que pode ser empregado em diversas áreas da indústria. A pesquisa foi satisfatória, visto que o resultado de DRX confirmou a presença de óxido de cálcio ao fím do processo de calcinação, concluindo assim que a obtenção de óxido de cálcio a partir da casca de ovo de galinha é possível. 


\section{REFERÊNCIAS}

BARBOSA, V.M, et al., Avaliação da qualidade da casca dos ovos provenientes de matrizes pesadas com diferentes idades, Arq. Bras. Med. Vet. Zootec., v.64, n.4, p.1036-1044, 2012.

CORRÊA, T. H. A.; MANHÃES, R. S. T.; HOLANDA, J. N. F. Conversão de resíduo de casca de ovo galináceo. In: ENCONTRO DE ENGENHARIA, CIÊNCIA DE MATERIAIS E INOVAÇÃO DO ESTADO DO RIO DE JANEIRO,1., 2015.

LACA, A.; DÍAZ, M. Eggshell waste as catalyst: a review. Chemical Engineering Journal, v. 197, p. 351-359, Oviedo, Espanha, 2017.

LEITE, F.H.G. Synthesis and characterization of calcium silicate insulating material using avian eggshell waste. Jornal Ceramics International, v. 43, p. 4674-4679, Campos dos Goytacazes, GO, 2017.

MOHAMMADI, M.; LAHIJANI, P.; MOHAMED, A. R. Refractory dopant-incorporated $\mathrm{CaO}$ from waste eggshell as sustainable sorbent for $\mathrm{CO}_{2}$ capture: Experimental and kinetic studies. Chemical Engineering Journal, Malásia, v. 243, p. 455-464, 2014.

NAGABHUSHANA, K.R.; et al. Thermoluminescence properties of $\mathrm{CaO}$ powder obtained from chicken eggshells. Jornal Radiation Physics and Chemistry, v. 138, p. 54-59, India, 2017.

NEVES, M. A. Alternativas para valorização da casca de ovo como complemento alimentar e em implantes ósseos. 1998, Dissertação (Mestrado). Departamento de Ciência e Tecnologia de Alimentos, Universidade Federal de Santa Catarina, Florianópolis, Brasil, 1998.

OLIVEIRA, D. A.; BENELLI, P; AMANTE, E. R. Valorização de resíduos sólidos: casca de ovo como matéria-prima no desenvolvimento de novos produtos. In: INTERNATIONAL WORKSHOPS ADVANCES IN CLEANER PRODUCTION, 2. 2009. Anais... São Paulo. 